\title{
AN EXPERIMENTAL STUDY OF PATHWAYS FROM THE BASAL GANGLIA
}

\author{
ARNE MOSFELD'T LAURSEN \\ Laboratory of Comparative Neurology, Department of Anatomy, \\ University of Michigan, Ann Arbor ${ }^{1}$
}

ELEVEN FIGURES

This paper is a contribution to the ever current discussion of the function and the connections of the basal ganglia. An attempt has been made to correlate so far as possible the results of this experimental study with the data available in the literature. However, it does not take the student of this region long to realize that such data are often confusing and extremely controversial. It seems probable that much of the difference of opinion is due to the fact that authors dealing with the subject have applied a variety of technics, none of which is sufficient alone to make possible definite conclusions. The limitations of the classical technic employed in the present study are recognized, and furthermore the material presented is small in amount. The author accordingly wishes to emphasize that the failure of the present material to confirm the connections described by some other authors cannot be regarded as a sufficient reason for a denial of their existence. However, the positive results here reported are regarded as offering documentation of certain connections which have been in dispute particularly since the appearance of the paper of Ranson and Ranson in 1941.

Funds for carrying out this research were obtained through grants from the Vera and Carl Johan Michaelsens Fund of

${ }^{1}$ Present address: Anatomisk Institut, Noerre Alle, Copenhagen, Denmark. 
Copenhagen, Denmark, and from the Otolaryngological Research Fund of the University of Michigan. The author wishes to express his appreciation to the donors of these grants. He is indebted to Professor Elizabeth C. Crosby under whose careful direction this paper was planned and executed.

\section{MATERIAL AND METHODS}

Lesions were placed in the brains of three specimens of Macaca mulatta. After a survival period varying from two to 8 weeks the monkeys were sacrificed and perfused and the brains prepared for study by the Swank and Davenport ('35) modification of the Marchi technic.

In two of the monkeys lesions were placed by using the McCulloch stereotaxic instrument and the maps of the brain of the macaque published by Atlas and Ingram ('37). Stimulation was carried out, and its results observed before the lesions were made. For such stimulation a faradic current, testing voltages below 5 and frequencies between 5 and 50 per second, was used. In the third monkey a small incision was made in the exposed frontal and insular regions of the cortex, and tissue was removed from the interior of the brain by means of a small spoon-shaped rongeur.

Several times during the postoperative period the animals were examined neurologically to note the presence or absence of abnormal tonicity, tremor, spasticity, abnormal movement and other peculiarities of behavior such as their reactions to their surroundings as compared with that of normal monkeys. The results of these examinations are discussed later under "Physiological Results."

DESCRIPTION OF MATERIAL

Monkey 1

In this male monkey a lesion was placed in the right globus pallidus on March 14, 1952. Electrolytic lesions were made with a direct current of 3 mamp applied for one minute. A point in the center of the area to be destroyed had previously 
been stimulated with negative results. The operation was performed under light ether anesthesia. About 5 minutes after the withdrawal of the ether, the monkey's head was tilted downward and turned toward the side of the lesion. The eyes were held in forced conjugate deviation toward the same side. These signs disappeared in about two hours. The monkey had an uneventful recovery.

He showed no abnormal behavior in the period between this operation and the next which was performed on March 28th. On that date the left globus pallidus was stimulated and then destroyed by the same method used in the earlier operation. Destruction at two of the readings had to be omitted because of developing disturbances in the animal's respiration. Thus the lesion on the left side was smaller in extent than that on the right. None of the signs which were present after the withdrawal of the ether at the first operation were present in the immediate postoperative period following the second operation, but in the succeeding days it became apparent that there was a distinct change in the animal's behavior. He showed almost no spontaneous motor activity but sat quietly in his favorite corner for hours. He was not asleep and his expression was not immobile and staring but, on the contrary, rather depressed. He had no paresis and no abnormalities in muscular tone and no apraxia were apparent when he handled his food. In walking and climbing there was no apparent loss of automatic associated movements. Reflexes could not be examined because of the occurrence of a violent jerking whenever he was touched. These jerks were the only type of involuntary movements present. They affected the entire body of the monkey and looked somewhat like the reaction to an electric shock. The occurrence of these jerks made it impossible for the monkey to perform rapid movements (such as successful attempts to escape the hands of the examiner), but slower movements could be carried out in a normal way. The monkey was not at all tame as are monkeys with lesions in the posterior hypothalamus and the amygdala (Poirier, '52). 
It was interesting to note the difference in behavior between this monkey and normal monkeys when the examiner approached the cages. Normal monkeys start jumping wildly from corner to corner in the greatest excitement. The monkey in question (which had behaved normally before the operations) appeared to have fundamentally the same type of response, only he went through the exercises in "slow motion." Having once arrived at one corner in the cage it took him minutes to get started toward another corner.

On April 30th the monkey was sacrificed and the brain perfused and prepared for study after the Marchi method. The brain was sectioned in a frontal plane.

On the right side (fig. 1) the lesion involved the internal division of the globus pallidus in its entire ventrodorsal extent and the middle one-third of its rostrocaudal extent. Furthermore, there was a destruction of the white matter ventral to globus pallidus and of the lateral part of the optic tract, the lateral geniculate nucleus, the area olfactoria and the most dorsal part of the amygdala. Isolated from this continuous lesion was a small area of destruction in the very center of the lateral division of the globus pallidus.

The lesion on the left side (fig. 1) lies largely beneath the globus pallidus merely touching its ventral border. However, in the region just ventral to the globus pallidus, the lesion interrupts the outflow of fibers from the most ventral portions of this nucleus. Furthermore, the area of destruction involves the area olfactoria, the lateral parts of the substantia innominata, the most dorsal region of the amygdala, the lateral portion of the optic tract and the lateral geniculate nucleus.

\section{Monkey 2}

The brain of this female monkey was operated upon on the right side on June 26, 1952, and an electrolytic lesion was introduced. The result of stimulation was negative. Immediately after the withdrawal of the ether, the monkey's neck and spine were tilted toward the side of the lesion. The eyes 
were in forced conjugate deviation toward the same side. Otherwise the recovery was uneventful. In the first two days after the operation there was a slight left hemiplegia, but this disappeared within a week.

On July 3rd the monkey was operated upon on the left side and a lesion made in the globus pallidus. Again, after this operation, the monkey's head was tilted toward the side of the new lesion but, when this sign disappeared within two or three hours postoperatively, the only abnormal sign that could be observed was a slight right hemiparesis and this did not disappear during the postoperative period. The monkey did not move as willingly as a normal monkey, but the significance of this fact is of course highly questionable in view of the previously mentioned hemiplegia. She did not display the jerking movements or the extreme inactivity of Monkey 1. She was highly apprehensive when somebody entered the room or the cage, screamed incessantly and defended herself with considerable success when attempts were made to catch her.

Tone was difficult to estimate because of the right hemiplegia but it seemed to be normal on the left side. There were no unquestionably abnormal positions of the extremities, no cogwheel movements or spasticity and no involuntary movements. Reflexes were brisk, more so on the right than on the left side.

The animal was sacrificed July 16, 1952. The brain was perfused and prepared after the Marchi method and cut in the sagittal plane.

On the right side (fig. 3) the lesion is mainly dorsal to the globus pallidus. The destruction extends into the dorsal edge of both sections of the globus pallidus, occupies a part of the posterior limb of the internal capsule and reaches into the ventral nucleus of the dorsal thalamus. On the left side (fig. 2) the lesion takes most of the substance of the globus pallidus but leaves intact a rim of tissue along the basal limits of this nucleus. The lesion extends slightly into the 
posterior limb of the internal capsule and into the adjoining putamen.

\section{Monkey 7}

This was a male monkey which was operated upon on April 10, 1950. The lateral fissure and frontal eye field were exposed on the left side. Small incisions were made in the frontal eye field and in the island. By means of a small spoonlike rongeur, the gray substance was then removed from the caudate nucleus through the former incision and from the putamen through the latter incision. During the entire postoperative period the monkey had a right hemiplegia and he was not able to turn his eyes to the right. There was no tremor, no spasticity or cogwheel movements and no involuntary movements.

On April 26th the animal was sacrificed and perfused, and the brain was prepared for study after the Marchi method. The brain was cut in frontal sections.

On the left side (fig. 4) the lesion is large and extends inward from the surface of the frontal cortex and from the basal one-third of the island. It destroyed the extreme capsule, the claustrum, the external capsule and extended into both limbs of the internal capsule, the head of the caudate and the putamen. The lesion extends into the most lateral part of the lateral division of the globus pallidus and into the dorsal part of the amygdala.

\section{DISCUSSION \\ Anatomical results}

Mesencephalic connections. Such connections have been the subject of much dispute. They have repeatedly been described in human brains by authors working with chronic pathological material (von Monakow, 1895; the Vogts, '19; Riese, '24; Kodama, '29). This type of material indicates more particularly a close functional relationship between the structures found to be degenerated, rather than the existence, necessarily, of direct, uninterrupted neuronal connections. More- 
over the direction of conduction along the bundles in question often cannot be determined with certainty.

Acute experiments and the study of Marchi preparations have not settled the question. Wilson ('14) noted connections to the red nucleus. Morgan ('27) thought that some degenerated fibers emerging from an experimental lesion in the globus pallidus had wide distribution in the brainstem, bundles extending as far caudad as the medulla oblongata. However, many of the connections described by this observer had not been seen by those who preceded him nor have they been documented since his study. It seems possible that Morgan misinterpreted certain of the artefacts always present in abundance in Marchi preparations.

Ranson and Ranson ('41), because of the many discrepancies, discarded the entire literature on the subject and made a fresh start with a series of experiments on the macaque. The resulting Marchi preparations failed to show any connections from the globus pallidus to regions beyond the diencephalon. Consequently the authors denied the existence of the disputed mesencephalic connections. They stated, however, in their discussion of another problem, that the Marchi technic may not be sufficient for the demonstration of finely myelinated fibers.

In normal material, mostly in the macaque, direct mesencephalic connections have been described by various authors (Papez, '42; Woodburne, Crosby and McCotter, '46) but these observations do not exclude the possibility, as the authors state, that at least some of the fibers in question have synapsed in the nucleus of the field of Forel.

Ansa lenticularis. The lesion on the left side in Monkey 1 only touches the ventral edge of the internal division of the globus pallidus and the ansa is the only degenerated efferent tract from the pallidum. This makes it possible to follow the course of this tract as distinct from that of the lenticular fasciculus which the ansa joins in the field $\mathrm{H}$ of Forel. The ansa emerges from the lesion as a layer of fibers covering the internal division of the globus pallidus on its ventral side. 
These fibers curve around the lower border of the internal capsule in their course, some of them being intermingled with its most ventral fibers. The ansa then takes a dorsal and also slightly medial and caudal course until it approaches the fornix, which is descending through the field to the hypothalamus. In this position it makes a right-angled turn and can then be followed from section to section in a caudal direction as a loose mass of fascicles intermingled with the compact bundles of the columna fornicis, pars tecta. Beyond the prerubral field the ansa cannot be traced.

This of course does not provide a basis for a denial of a mesencephalic destination of the ansa. All that can be said is, that the present material does not demonstrate this connection beyond doubt. The diffusely spread out, stained fibers which are found over most of the midbrain may very well be degenerated fibers from the ansa but, unfortunately, single fibers cannot be differentiated from artefacts with anything approaching certainty.

Whether or not some of the fascicles of the ansa originate in regions outside the globus pallidus cannot be determined from the available material. Kodama ('29) and Woodburne, Crosby and McCotter ('46) described the bundle as having its origin in both the globus pallidus, the putamen and the substantia innominata. The extreme opposite viewpoint was held by the Ransons ('41a and b). These authors claimed that the ansa has its origin entirely from the internal division of the globus pallidus. They based their claim on the fact that interruption of the ansa in the ventral thalamus produces cell degeneration in only this small part of the nucleus. Monkey 7 had a lesion which only damaged the lateral part of the lateral division of the globus pallidus. In this monkey there was unquestionable degeneration in both the ansa and the lenticular fasciculus (fig. 8). As a matter of fact, the amount of degenerated fibers in the ansa and in the lenticular fasciculus was so impressive that in the author's opinion the small part of the globus pallidus included in the lesion could not have constituted the only origin of these fibers. A con- 
tribution to the ansa from the putamen must be considered highly probable.

However, the lesion in Monkey 7 was large and each of the destroyed structures offer a possible origin for degenerated fibers found in the ansa. Several reports are available in the literature on isolated experimental lesions in the putamen and the amygdala and the Marchi preparations prepared from such material have, so far as the author knows, never demonstrated degeneration in the ansa. Negative evidence, however, can hardly be accepted on the basis of Marchi material and obviously the positive evidence in favor of a complex origin of the ansa presented by Kodama ('29) and others carries far greater weight. A possibility, which in the author's opinion requires more consideration, is a contribution to the ansa from the insular or temporal cortex. Normal material in Weil preparation is actually highly suggestive in this respect. The same was also indicated in the study of Ranson, Ranson and Ranson ('41a) in which fibers from the temporal lobe were found to pass ventral to the putamen.

Lenticular fasciculus (fig. 6). This bundle is degenerated on the right side in the brain of Monkey 1 . The lesion occupies the middle third of the internal division of the globus pallidus in its entire ventrodorsal extent. The fibers emerge from the dorsal part of the lesion, traverse the internal capsule and collect in a discrete bundle between the subthalamic nucleus betow and the zona incerta above. The fibers then join the ansa bundle, which, $1 \mathrm{~mm}$ more rostrally, had entered the field $\mathrm{H}$ of Forel and the field just medial to it where it is intermingled with the columna fornicis, pars tecta. The field of degenerated fibers in which the ansa cannot be distinguished from the lenticular fasciculus can be followed caudad to the prerubral region where suddenly a reduction in the amount of fibers appears. This reduction coincides, on the right side, with the complete disappearance of the ansa on the left side. The remaining fibers can be followed as a more diffuse, but still easily recognizable bundle into the red nucleus where the fibers are most concentrated in its 
most dorsomedial part (fig. 7). The dorsomedial part of the red nucleus is described as the termination of the ventral part of the $\mathrm{H}_{2}$ bundle dealt with in the work of Woodburne, Crosby and McCotter from 1946. Scattered degenerated fibers are found in the tegmentum immediately dorsal to the red nucleus (pars dorsalis of the nucleus mesencephalicus profundus) and in lesser concentration in most of the midbrain tegmentum, but as already mentioned, scattered degeneration cannot be distinguished in this material from artefacts with sufficient certainty.

In the sagittal sections prepared from Monkey 2 the lenticular fasciculus is interrupted by a lesion cutting into the dorsal part of the globus pallidus. Degenerated fibers are found in the red nucleus and in the tegmentum immediately dorsal to it with a heavy accumulation of fibers in the dorsomedial part of the nucleus. The fibers bending around the medial edge of the zona incerta on their way from the $\mathrm{H}_{2}$ to the $\mathrm{H}_{1}$ bundle are nicely demonstrated in the present material (fig. 10). The existence of this loop was convincingly demonstrated by the Ransons ('41) who carried it to the nucleus ventralis anterior in the dorsal thalamus and confirmed for normal material by Papez ('42) and in degeneration material by Woodburne, Crosby and McCotter ('46) who carried it to the nucleus ventralis lateralis. In this connection it may be worthy of mention that in the present material no fibers passed from the globus pallidus to the dorsal thalamus by way of the ansa as described by Riese ('24) and Kodama ('29) nor could such fibers be found in the inferior thalamic peduncle as described by Kodama ('29). The writer wishes to restress that the lesion in the monkey in question was confined to a limited part of the globus pallidus and that it consequently cannot be expected to interrupt all efferent fibers from this nucleus.

Subthalamic fasciculus. The dual connections interrelating the striatal areas with the subthalamic nucleus, which are represented in the subthalamic fasciculus, are generally agreed upon by workers dealing with the connections of the basal 
ganglia (the Vogts, '19; Riese, '24; Kodama, '29; Papez, '42; Mettler, '45; the Ransons, '41, '41a, '41b), consequently a detailed account is not of interest. A few points may deserve mention. The observation of Mettler, that the fibers of the subthalamic fasciculus mostly terminate in the lateral large celled portion of the subthalamic nucleus appears to be documented in the material used for the present study. The observation of Ranson that the fibers in question are of a particularly small caliber could not be confirmed. In the slides available no significant difference in caliber between the bundles of the subthalamic fasciculus and those of the ansa was apparent.

Pallido-incertal fibers. Fibers of this character have been observed by Kodama ('29) and by Woodburne, Crosby and McCotter ('46) but were earlier denied by Wilson ('14). The present material shows fibers turning from the lenticular fasciculus into the substance of the zona incerta, including the most medial part of this area, which is sometimes labeled separately as the nucleus of the field of Forel (fig. 6).

Pallido-hypothalamic fascicles. Connections between the globus pallidus and the hypothalamus are generally recognized (von Monakow, 1895; the Vogts, '19; Kodama, '29; and others). These authors described the fibers as ending in the tuber cinereum and as being a part of one of the supraoptic commissures. Krieg ('32), working on the albino rat, found the termination to be the ventromedial hypothalamic nucleus and he employed the term hypothalamic fasciculus for this connection. Bard and Rioch ('37) introduced the term pallido-hypothalamic tract, which has since then been widely accepted (Vidal, '40; Ranson and Ranson, '41; Papez, '42; Mettler, '45; and others) sometimes meaning all the fibers going from the pallidum to the various parts of the hypothalamus, sometimes signifying only fibers turning off from the lenticular fasciculus to terminate in the ventromedial hypothalamic nucleus. No attempt will be made here to discuss the value of any terminology. In the present material a distinctly fine fiber bundle is seen to detach itself from the 
ansa. The tract takes a ventral course with a slightly medial and rostral tilt to end in the region immediately rostral and medial to the mammillary body (fig. 5). Woodburne, Crosby and McCotter ('46) used the term tractus pallido-hypothalamicus for a corresponding bundle observed in normal material of the macaque brain.

Lateral cortico-habenular fibers. Fibers of medium caliber emerge from the lesion on the left side of the brain of Monkey 1. The fibers come from the most rostral part of the lesion at a level at which the lesion is confined entirely to the region below the globus pallidus. Some of the fibers pass dorsally through the globus pallidus, others curve medially around the medial edge of this nucleus before they turn dorsad (fig. 9 ). All of the fibers collect in a bundle which takes a direction that is mainly dorsal, but also slightly medial and rostral, so that the bundle passes immediately in front of the anterior pole of the dorsal thalamus. The bundle here has the genu of the internal capsule on its lateral side and the columna fornicis, pars libera, on its medial side. The fibers then curve dorsally, spreading out along the dorsal surface of the dorsal thalamus. Followed caudad the fibers are seen to occupy the stratum zonale, intermingled with the stria terminalis laterally and the stria medullaris medially. The majority of the fibers terminate in the lateral habenular nucleus, a few end in the medial habenular nucleus and a limited number follow the stria terminalis into the roof of the inferior horn of the lateral ventricle (fig. 11). Whether or not fibers cross in the habenular commissure, as described by the Ransons ('41), unfortunately could not be determined.

The description of lateral cortico-habenular fibers given here corresponds otherwise with that given by the Ransons. The mentioned fibers have earlier been observed by Wilson and several others. The Ransons were not able from their material to tell whether the fibers emerged from the amygdala and then traversed the globus pallidus, or whether they had their origin in the globus pallidus itself. The present study gives an answer to this question. The lesion on the left side 
only touches the basal edge of the globus pallidus, and the amount of cells removed from this nucleus cannot possibly be responsible for the amount of degeneration observed. The fibers have their origin from the region below the globus pallidus, probably the amygdala.

The described fibers have occasionally been termed amygdalo-habenular fibers, but are traditionally designated lateral cortico-habenular. They have usually been described as originating in the pyriform lobe and the amygdala (Ariëns Kappers, Huber and Crosby, '36).

Attention is called to a relationship which is frequently a cause of mislabeling. In the subthalamic region a continuous set of fibers are found spread out in a rostrocaudal direction. They are all found in about the same position on frontal sections, and they are all extending dorsocaudad at about the same tilt. Of these fibers the most rostral are amygdalohabenular, then the inferior thalamic peduncle and finally the ansa lenticularis. The two former bundles are often mislabeled ansa lenticularis.

No degeneration was observed in the inferior thalamic peduncle. This may lend support to the view of Papez ('42) that the fibers of the peduncle conduct from the thalamus to the pallidum and surrounding structures. This view was also held by the Vogts while Kodama claimed the direction of conduction to be from the pallidum to the dorsal thalamus. (For further references see Ariëns Kappers, Huber and Crosby.) The support given to Papez' view should be taken with reservation since the lesion in Monkey 1 probably did not interrupt all efferent fibers from the globus pallidus.

Pallido-tectal fibers. Kodama has described a connection between the globus pallidus and the superior colliculus. In the present material no degeneration was found in the tectum. This may be worthy of emphasis in another connection. As previously described, the lesion involved a considerable part of the optic tract and the lateral geniculate nucleus in Monkey 1. Although this resulted in marked degeneration in the geniculo-calcarine tract no degeneration could be followed to 
the tectum. This may serve as another example of the minor rôle played by the superior colliculus in the optic reflexes in primates.

Intrapallidal fibers. The Vogts denied the existence of short intrapallidal fibers. Kodama's material gave support for the belief that short fibers connect the lateral to the medial segment of the globus pallidus. The Ransons ('41) denied this and stated that intrapallidal fibers may exist, but that they conducted in the reverse direction. The present material demonstrates the latter type of fibers. On the right side where the lesion occupies the medial segment of the globus pallidus considerable degeneration can be found in the lateral segment also. However, the denial expressed by the Ransons must be looked upon with reservation for reasons previously discussed. A reasonable conclusion is, that the two segments of the globus pallidus are interconnected.

Efferent connections from ganglion basale of Meynert. On the left side in Monkey 1 the region ventral to the globus pallidus was destroyed. The sublenticular part of the basal ganglion of Meynert is thus included in the lesion. Kodama ('29) has described fibers extending dorsally from this nucleus to terminate in the putamen, the dorsomedial nucleus of the thalamus and the tuber cinereum. In the present slides no such fibers could be seen emerging from the lesion. It is possible of course that such fibers are unmyelinated or of very small caliber and so not evident in the available material.

\section{Physiological results}

In a monkey with a small electrolytic lesion confined to the upper portion of the globus pallidus on both sides no signs were detectable. This result is in accordance with those of Wilson ('14), Ranson and Berry ('41), Kennard ('44) and others. The simplest explanation for these negative results is the one suggested by Mettler ('40) and again by Kennard ('44) that the remaining cells in the pallidum are able to carry out the functions of this nucleus adequately. The ex- 
planation by these authors is supposed to imply that no focal representation exists in the pallidum such as has been indicated also by several experiments (Mettler, Ades, Lipman and Culler, '39; Kennard, '44).

A monkey with a large unilateral destruction of the striatum and the internal capsule showed a contralateral spastic paresis but no abnormal behavior which could be ascribed to the lesion of the striatum. This result parallels the observation of Kennard and Fulton ('42) that no indications of abnormality in function of the basal ganglia are present in case of a concomitant contralateral paresis.

Abnormal behavior was observed in one case in which a lesion interrupted the ansa (or most of the ansa) bilaterally and most of the remaining efferent fibers from the globus pallidus unilaterally together with a unilateral involvement of the structures immediately basal to the globus pallidus. The signs displayed by this monkey were a peculiar jerking previously described in detail and a very marked poverty of movements. The symptoms bear some resemblance to the clinical signs of disease of the basal ganglia in man. In some clinical cases the poverty of movements is very conspicuous and not accompanied by any tremor, chorea or athetosis. However the monkey's condition does not amount to a reproduction of any well known syndrome. This is not surprising in view of the marked species differences found between primates in the study of Kennard ('44). Signs of the same character as those described for this monkey have been reported by several authors working with the macaque (Mettler and Mettler, '42; Kennard, '44), but they have always been described as transient, as affecting more particularly the upper than the lower extremity and as affecting exclusively the side contralateral to the lesion. In the present case the jerking and the poverty of movements involved the monkey's entire body. It persisted undiminished and unchanged during an observation period of 8 weeks. 


\section{SUMMARY}

Lesions were placed in the basal ganglia in three specimens of Macaca mulatta. The animals were observed during a survival period of from two to 8 weeks. The brains were studied in Marchi preparations. The following results were obtained:

1. The origin of the ansa lenticularis is not confined to the medial division of the globus pallidus. Additional possible sources are the lateral division of the globus pallidus and the putamen. The tract may be joined by fibers from the temporal and insular cortex.

2. Fibers from the basal ganglia were followed into various areas of the dorsal and the ventral thalamus and the hypothalamus and into the red nucleus of the mesencephalon.

3. The origin of the lateral cortico-habenular tract is basal to the globus pallidus, presumably in the amygdala and the pyriform lobe cortex.

4. Small electrolytic lesions in the globus pallidus result in no detectable abnormalities in behavior in the macaque.

5. A lesion destroying the globus pallidus unilaterally and interrupting the fibers basal to the globus pallidus bilaterally produce a marked reduction in the monkey's willingness to move. Peculiar jerks occurred whenever this monkey was touched.

\section{LITERATURE CITED}

Arikins Kappers, C. U., G. C. Huber AND E. C. Crosby 1936 The comparative anatomy of the nervous system of vertebrates including man. 2 vols. Macmillan Co., New York.

AtLAS, D., AND W. R. INGRAM 1937 Topography of the brainstem of the Rhesus monkey with special reference to the diencephalon. J. Comp. Neur., $66: 263-289$.

BARD, P., AND D. MoK. Rioch 1937 A study of four cats deprived of neocortex and additional portions of the forebrain. Bull. Johns Hopkins Hosp., 60: $73-147$.

KENNARD, M. A. 1944 Experimental analysis of the functions of the basal ganglia in monkeys and chimpanzees. J. Neurophysiol., 7: 127-148.

KenNard, M. A., AND J. F. FUtmon 1942 Corticostriatal interrelations in monkey and chimpanzee. Res. Publ. Assoc. Nerv. Ment. Dis., 21: 228-245. 
KodAMA, S. 1929 Über die sogenannten Basalganglien und ihre Adnexe. (Morphogenetische und pathologischanatomische Untersuchungen.) Schweiz. Arch. f. Neur. u. Psychiat., 23: 38-100, 179-265.

KRIEG, W. J. S. 1932 The hypothalamus of the albino rat. J. Comp. Neur., $55: 19-89$.

Mettler, F. A. 1940 Relation between pyramidal and extrapyramidal function. Res. Publ. Assoc. Nerv. Ment. Dis., 21: 150-227.

1945 Fiber connections of the corpus striatum of the monkey and baboon. J. Comp. Neur., 8. : 169-204.

MetTler, F. A., W. H. Ades, E. Lipman ANd E. A. Culler 1939 The extrapyramidal system. Arch. Neur. Psychiat., 41: 984-995.

Mettler, F. A., ANd C. C. MetTler 1942 The effect of striatal injury. Brain, $65: 242-255$.

MONAKow, C. voN 1895 Experimentelle und pathologisch-anatomische Untersuehungen über die Haubenregion, den Sehhügel und die Regio subthalamiea, nebst Beiträge zur Kentniss früher erworbener Gross und Kleinhirn Defecte. Arch. Psychiat. u. Nervenkr., 27: 1-128, 386-478.

MoRgan, L. O. 1927 The corpus striatum. A study of secondary degeneration following lesions in man and acute symptoms following experimenta] lesions in cats. Arch. Neur. Psychiat., 18: 495-549.

PAPEZ, J. W. 1942 A summary of fiber connections of the basal ganglia with each other and with other portions of the brain. Res. Publ. Assoc. Nerv. Ment. Dis., 21: 21-68.

Polrier, L. J. 1952 Anatomical and experimental studies on the temporal lobe of the macaque. J. Comp. Neur., 96:209-248.

RANSON, S. W., AND S. W. RANson, JR. 1941 Efferent fibers of the corpus striatum. Res. Publ. Assoc. Nerv. Ment. Dis., 21: 69-76.

Ranson, S. W., S. W. Ranson, JR., and M. Ranson 1941a Fiber connections of corpus striatum as seen in Marchi preparations. Arch. Neur. Psychiat., 46: 230-249.

$1941 \mathrm{~b}$ Corpus striatum and thalamus of a partially decorticate monkey. Arch. Neur. Psychiat., 46: 402-415.

RANSON, S. W., AND C. BERRY 1941 Observations on monkeys with bilateral lesions in the globus pallidus. Arch. Neur. Psychiat., 46: 504-508.

RIESE, W. 1924 Beiträge zur Faseranatomie der Stammganglien. J. f. Psychol. u. Neur., 31: 81-122.

SwaNk, R. L., AND H. A. DAVENPORT 1935 Chlorate-osmic-formalin method for staining degenerating myelin. Stain Tech., 10:87-90.

VOGT, O, AND O. VoGT 1919 Zur Kentniss der pathologischen Veränderungen des Striatum und des Pallidum zur Pathophysiologie der dabei auftretenden Krankheitserscheinungen. Sitzung d. Heidelberger Akademie d. Wissensehaften. Math. Naturwiss. Kl., Abteil B., Biol. Wissensch. Abhandlung, $14: 3-56$.

VIDAL, F. 1940 Pallido-hypothalamic tract or X-bundle of Meynert in the Rhesus monkey. Arch. Neur. Psychiat., 44: 1219-1223.

WILson, K. 1914 An experimental research into the anatomy and physiology of the corpus striatum. Brain, $36: 427-492$. 
Woodburne, R. T., E. C. Crosiy and R. E. MCCoTter 1946 The mammalian isthmus and midbrain region, Part II. The fiber connections. A. The relation of the tegmentum of the midbrain with the basal ganglia in Macaca mulatta. J. Comp. Neur., 85: 67-92. 


\section{PLATES}

\section{ABBREVIATIONS}

ANS. L., ansa lenticularis

AQ., aqueductus cerebri

C. G. L., corpus geniculatum laterale

C. G. M., corpus geniculatum mediale

C. M., corpus mammillare

CM. P., commissura posterior

CP. I., capsula interna

CP. I. G., capsula interna, genu

GP. I. P., capsula interna, crus posterius

F. HIP., fasciculus habenulo-interpeduncularis

FIM., fimbria

FOR., fornix

GL. P., globus pallidus

GL. P. CR. I, globus pallidus, crus I

GL. P. CR. II, globus pallidus, crus II

H. I, field $\mathrm{H}_{\mathbf{i}}$ of Forel

H. II, field $\mathrm{H}_{2}$ of Forel

N. AM., nucleus amygdalae

N. C., nucleus caudatus

N. H. M., nucleus habenularis medialis
N. L., nucleus lenticularis

N. I. TH., nucleus lateralis thalami

N. M. TH., nucleus (dorso) medialis thalami

N. RUB., nucleus ruber

N. SBTH., nucleus subthalamicus

N. V. TH., nucleus ventralis thalami

PS. P., pes pedunculi

PUL., puivinar thalami

SB. N., substantia nigra

ST. M., stria medullaris

ST. T., stria terminalis

TH., thalamus

T. PAHY., tractus pallido-hypothalamicus

T. II, tractus opticus

VE. L., ventriculus lateralis

VE. III, ventriculus tertius

Z. I., zona incerta

II, nervus opticus

III, nervus oculomotorius 
PIAATE 1

EXPLANATION OF FIGURES

1 Diagram of frontal section showing the position of the lesions in Monkey 1. Rostrocaudally the extent of the lesions correspond to the middle one-third of the globus pallidus.

2 Diagram of sugittal seetion showing the position of the lesion on the left side in Monkey 2.

3 Diagram of sagittal section showing the position of the lesion on the riglit side in Monkey 2.

4 Diagram of a frontal section showing the position of the lesion in the brain of Monkey 7 . 


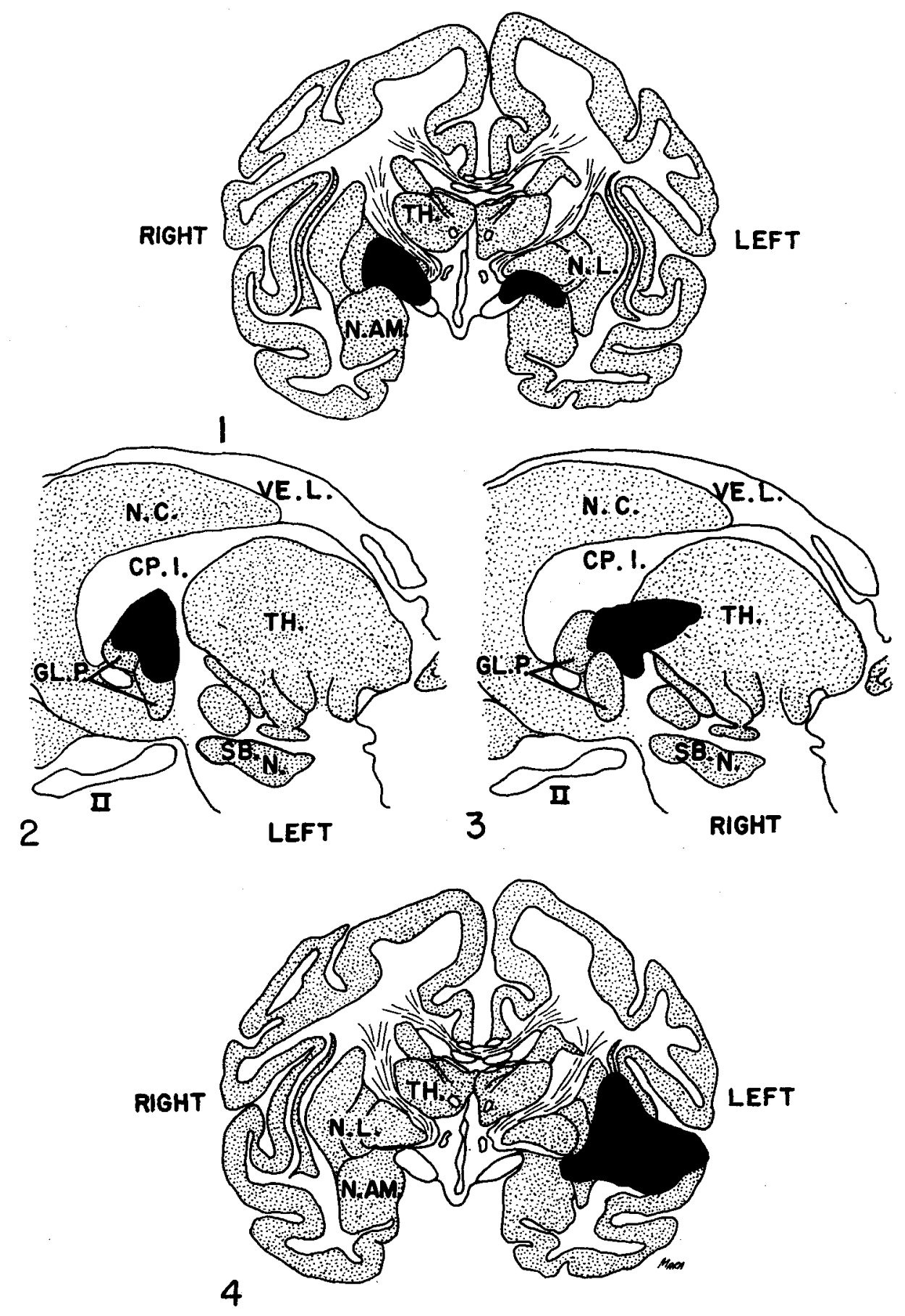




\section{PLATE 2}

EXPLANATION OF FIGURES

5 A photomierograph of a frontal section through the tuber region of Monkey 1 . The lesions are shown in the lateral parts of the figure. Degenerated fibers of the ansa lenticularis and the pallido-hypothalamic tract can be seen on both sides. The fibers immediately dorsal to the optic tract belong to the commissure of Meynert. Marchi preparation. $\times 10$.

6 A photomicrograph of the region of the mammillary body in the same brain illustrated in figure 5. On the right side of the brain (the left side of the figure) the lenticular fasciculus has entered the ventral thalamus after interdigitating with the fibers of the internal capsule. In the region corresponding to the fiold $\mathrm{H}$ of Ford, the ansa and the lenticular faseiculus are seen to join. each othor. Marchi preparation. $\times 10$.

7 A photomicrograph of the same brain illustrated in the two previous figures but taken at midbrain levels. The degenerated fibers from the globus pallidus (x) are illustrated in the red nucleus. Notice that precipitate is present in the third nerve on both sides. Marchi preparation. $\times 10$. 
PATHWAYS FROM BASAL GANGLIA

PLATE 2 ARNE MOSFELDT LAURSEN
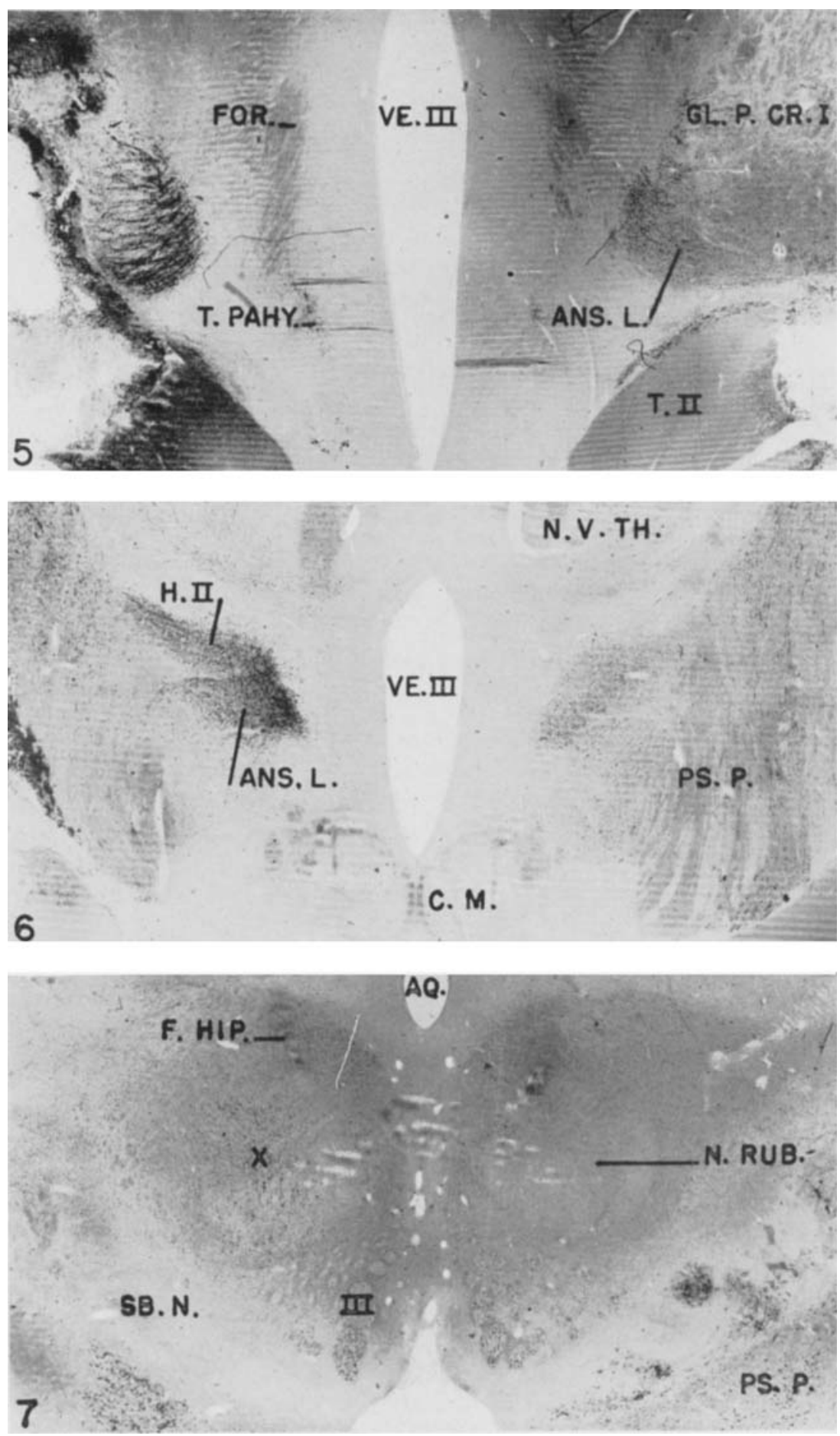


\section{PLATE 3}

\section{EXPLANATION OF FIGURES}

8 A photomierograph of a frontal section through the tuber region of the brain of Monkey 7. The lesion which has involved the putamen and the most lateral border of the lateral division of the globus pallidus can be seen on the right in the figure (left in the brain). The demarcation between the lateral and the medial divisions of the globus pallidus can be seen faintly. The boundary between the two is represented by a line which is strongly convex lateralward and is seen most elearly in the dorsal part of the globus pallidus. Degenerated fibers in the ansa lie ventral to the internal capsule. Marchi preparation. $\times 10$.

9 A photomicrograph of a frontal section from the brain of Monkey 1 . The level of section is just rostral to the rostral pole of the dorsal thalamus. Degenerated amygdalo-habenular fibers (the lateral cortico-habenular tract of many observers) are seen emerging from the lesion in the lower right hand corner of the figure (left side of tho brain) and to eurve partly through the substance of the globus pallidus. Marchi preparation. $\times 10$.

10 A photomicrograph of a frontal section from the region of the manmillary body of Monkey 7. Degenerated fibers from the lenticular fasciculus $\left(H_{1}\right)$ loop around the medial end of the zona incerta and join the thalamic fas ciculus $\left(\mathrm{H}_{2}\right)$ to reach the ventral nucleus of the thalamus. $\times 10$.

11 A photomicrograph of a frontal section through the posterior commissure of the brain of Monkey 1. The stria medullaris ends in the lateral habenular nucleus and the stria terminalis extends into the roof of the inferior hor' of the lateral ventricle. Marchi preparation. $\times 10$. 

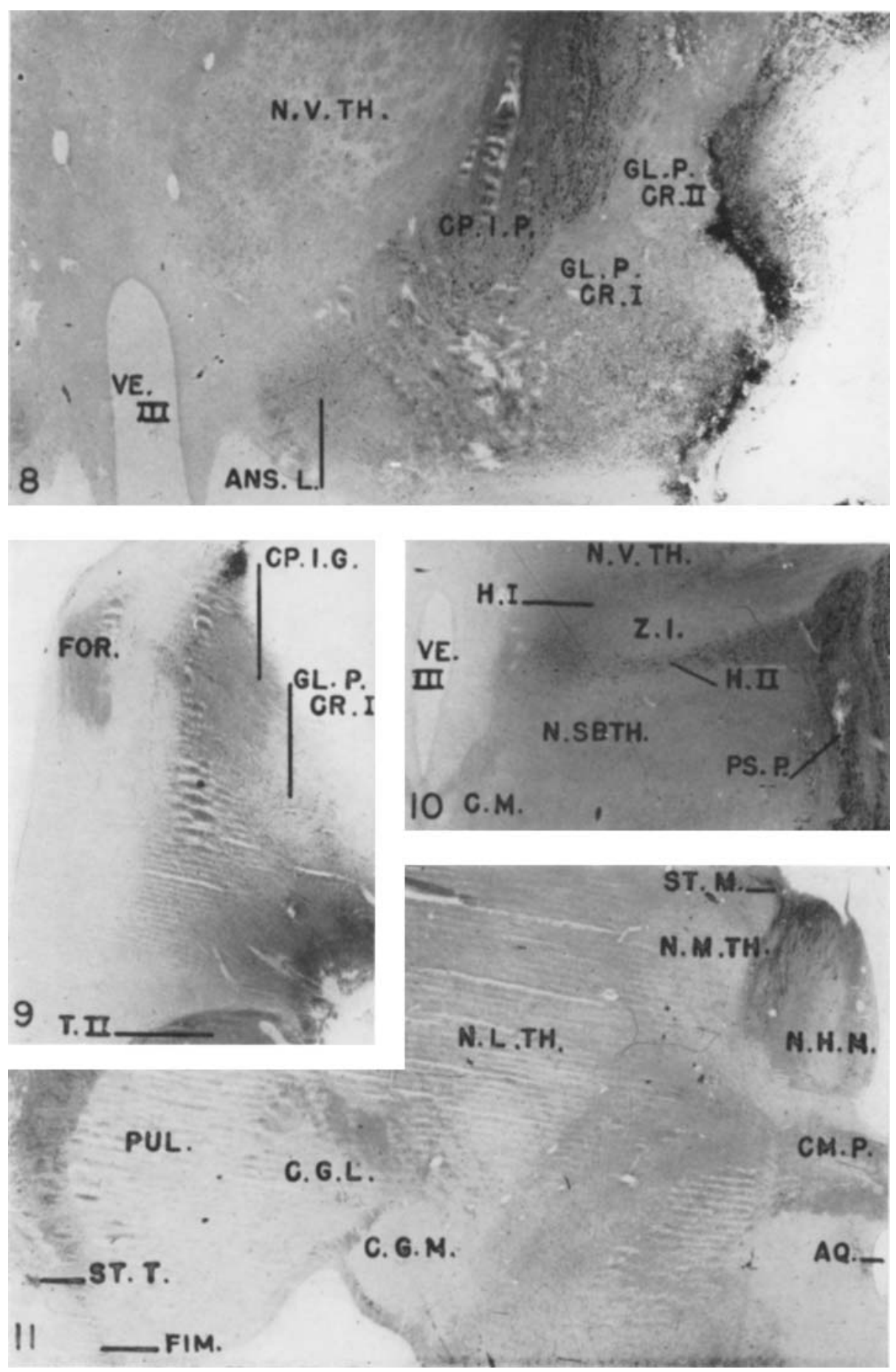